\title{
Are First Year Undergraduates Mathematically Resilient? A Comparison of a STEM and a non-STEM Discipline in an Institute of Technology
}

\author{
Louise Duggan, Pamela Cowan, Ian Cantley \\ Queen's University \\ Belfast
}

\begin{abstract}
The Transition from post-primary to higher education presents many challenges for students, both personally and academically. Widespread concern regarding students' lack of mathematical preparedness when negotiating the transition to higher education has also been widely documented. The issue of mathematical preparedness is colloquially referred to as the 'Mathematics problem' in the literature and specifically refers to the level of mathematical preparedness and skills of students as they commence their undergraduate studies. Mathematics is considered an important component of many degree programs and many students struggle with the mathematical demands of their degree programs due to inadequate and negative prior experiences. The number of disciplines affected by the existence of the 'mathematics problem' has also broadened to include disciplines classified as soft pure and soft applied. Several reasons are said to have contributed to the 'mathematics problem' within the Irish context and in an attempt to alleviate these concerns and to enable a smooth transition to higher education, the Irish government introduced the Project Maths curriculum. This paper reports on first year undergraduate students' experiences of the Project Maths curriculum and provides insight into whether students' 'mathematical resilience' prepares them for their higher education course.
\end{abstract}

\section{Introduction}

Manifestation of the 'mathematics problem' typically occurs in the first year of undergraduate studies and is characterized by the following:

1. A lack of core mathematical knowledge and skills which would be expected at the transition to higher education [1];

2. A lack of fluency in applying mathematics and specifically an inability to solve and model unfamiliar problems [1] and

3. Students not studying sufficient mathematics prior to entry into higher education [2].

Consensus exists that the inability of students to successfully negotiate the transition to tertiary level mathematics is as a result of discrepancies between what students encountered in mathematics at school and what they are exposed to at third level [3], which leads to a "cooling off", a loss of enthusiasm for the subject and subsequent disengagement [4]. Low retention rates within the STEM disciplines are also attributed to difficulties associated with the mathematical content of many higher education courses [5].

Several reasons are said to have contributed to the 'mathematics problem' within the Irish context including the policy of widening access to higher education which inevitably leads to variability in mathematical entry standards, large class sizes in higher education, changes in pedagogical approaches and general difficulties associated with the transition to higher education [6]. The Irish Leaving Certificate and the points system which is primarily used for selection purposes to higher education have exacerbated the situation [7]. The consequence of the 'mathematics problem' is such that many higher level institutions in Ireland now provide remedial support for those learners deemed 'at risk'.

Project Maths was introduced by the Irish government in an attempt to alleviate the difficulties associated with mathematics instruction and to enable a smooth transition to higher education [8]. The Project Maths curriculum attempts to foster in all learners five key skills including information processing, being personally effective, communicating, critical and creative thinking and working with others [8]. These key skills were identified as being important for all learners to maximise their potential, both in school and into their future careers.

\section{Literature review}

Research indicates that negotiating the transition from post-primary to higher education is a difficult time for many students both personally and academically e.g. [9], [10] and [11]. It is claimed in [11] that 'tertiary students' experiences during their first year of study appear to be crucial to their personal adjustment and academic performance' (p. 1) and problems associated with adjustment can result in students dropping out or deferring their courses. It is stated in [10] that it is during this 
transitional period that 'many students experience stress associated with academic concerns and encounter difficulties adjusting to an environment that presents new academic and social demands' ( $p$. 3). The ease with which students negotiate the transition depends on how students adapt to different learning styles and their ability to become independent learners [9].

Over the past number of years, concerns have been raised in Ireland in relation to the mathematical ability and skills of students transitioning to higher education ([12] and [13]) and the problem is much more prevalent at smaller higher education institutions where enrollments are much lower [14]. Mathematical preparedness is specifically concerned with the level of preparation that students receive in post-primary school in advance of their third level studies. Many terms are used in the literature to describe mathematical preparedness including mathematical readiness, college readiness, mathematical literacy and quantitative literacy, while the term 'mathematics problem' is specifically concerned with the sub-standard mathematical knowledge and skills of students progressing to higher education.

Transitioning from second level to higher education is theorized in [15] as a 'rite of passage'. Two important aspects of the transition identified by [15] included cognitive conflict and culture shock. The paper concluded by stating that the transition from second level to third level cannot occur outside a 'proper environment'. A successful transition can be tentatively described as accomplishing most of: the individual feeling a sense of belonging in their new role as a higher education student, the individual can achieve and work towards their goals, the individual shows good academic progress, the individual has support (both academic and otherwise), and can access it when needed and the individual enjoys mathematics [15].

Research conducted by [3] from the Irish context, suggested that the root of the 'mathematics problem' was the result of a mismatch in the experiences of mathematics at post-primary level and the subsequent high expectations of mathematicsintensive courses at third level. The authors conducted a study of two second level mathematics classrooms. They found issues with students being taught using rote learning methods and exam focused instruction. The findings of their research seem to concur with the culture shock described by [15] during the transition to higher education and the resulting negative effect on students upon arrival in a third level mathematics classroom.

College readiness as defined by [16] is described as 'the level of preparation a student needs in order to enrol and succeed - without remediation - in a credit-bearing general education course at a postsecondary institution that offers a baccalaureate degree or transfer to a baccalaureate program' (p. 5). Applying Conley's definition, mathematics college readiness is a student's ability to be successful in college-level mathematics courses without the need for remedial or developmental coursework [16]. A number of factors have been identified as being relevant in determining whether learners are college ready [17], including factors from the cognitive and non-cognitive domains. Residing in the cognitive domain are content knowledge and cognitive skills; students need to have acquired core mathematical knowledge as well as problem solving, critical thinking, communication and metacognition skills. Non-cognitive factors include attitudes, behaviors, mindsets as well as campus integration factors. Academic behaviours enable students to engage with content and maximise their learning [16]. College ready students also display a strong relationship with themselves and with others encompassing traits such as self-awareness and self-esteem. College ready students have developed a career-oriented identity in that they can identity their goals and recognise their strengths and weaknesses and understand how they fit into the larger campus community [16].

\section{Project Maths}

The Irish government recognised difficulties associated with mathematics instruction in 2005, and following a consultation process in 2006, the Project Maths curriculum was proposed [8]. Particular concerns identified include the following:

- Over-emphasis on procedural skills and rote learning to the detriment of understanding;

- Declining interest in mathematics and lack of commitment on the part of the students to making the effort required to understand the subject;

- $\quad$ Poor attitudes towards mathematics;

- Low levels of understanding on the part of students progressing to third-level education, even among those who had studied mathematics at higher level;

- A lack of in-depth knowledge by some teachers of mathematics, who tended to operate in a narrow 'comfort zone'.

As a result of these concerns and the concerns of the Irish government, Project Maths was introduced on a phased basis commencing in September 2008, with full implementation completed in September 2015. As well as improving attitudes towards mathematics in general one of the other aims of the Project Maths curriculum is to ease the mathematical transition to higher education [8].

Project Maths is based on socio-cultural theory which posits that students learn collaboratively and that language plays a central role in the development 
of their higher mental processes. In a socio-cultural learning environment, students are challenged to become active participants, while the teacher is no longer considered the provider of knowledge but rather the creator of a classroom environment which fosters engagement. Characteristics typical of the socio-cultural learning environment and implied by the Project Maths curriculum include: linking scientific and everyday knowledge by means of real world problems; allowing students the freedom to explore their own understandings and ideas with fellow students; mediating students' actions by material and symbolic tools; scaffolding - by means of the zone of proximal development and facilitating disclosure within the mathematics classroom [18]. The teacher and student must work collaboratively together until common knowledge ideally emerges and both must assume ownership of this knowledge and, eventually the students become more independent learners.

\section{Mathematical Resilience}

The concept of, and influence of mathematical resilience often referred to as academic mindsets cannot be underestimated [20] and in fact [22] claim that mindsets are much more important in understanding students' mathematical preparedness for higher education more so than grades. Mathematical resilience closely associated to academic mindsets describes the positive attributes which enable learners to engage with, learn and use mathematics both in school and beyond. There are four aspects to mathematical resilience all of which are dependent on:

1. having a growth mindset, such that learners believe their mathematical capabilities can be developed through dedication and hard work;

2. knowing that mathematics can be of personal value, is of value in the world and that the learner is valued within the community of learners;

3. knowing how to work at learning mathematics, and;

4. knowing how to find appropriate support to stay in the 'growth zone' [22].

[22] developed the construct of 'mathematical resilience' in order to enable learners of mathematics, and those engaged in helping them learn mathematics, to act differently and thus mitigate the establishment of negative attitudes towards mathematics. It works in opposition to, and equips learners to address, the negative attitudes, anxiety and helplessness that frequently accompany learning mathematics. Learners who are mathematically resilient are better positioned to continue the study of mathematics. Educational research reveals a number of factors, such as mathematics anxiety and phobia, learned helplessness all of which tend to emphasize difficulties associated with learning mathematics [22]. The literature investigating these constructs does offer ideas and suggestions for treatment of such issues, but generally does not offer suggestions on ways in which mathematics can be taught to mitigate these factors. [22] describe mathematical resilience as a positive construct that enables students to develop a positive stance towards mathematics.

The concept of resilience which exists in wider psychological literature describes the phenomenon in which some learners succeed despite significant adversity. Subsequently, [22] found four aspects deemed important in mathematically resilient learners. Negative emotions are said to be frequently engendered by many traditional approaches to teaching mathematics [22]. Mathematics anxiety and mathematics avoidance are important factors in considering mathematical resilience since these phenomena are prevalent in many countries [22]. Widespread concern about the decline in students' preparedness to study mathematics or to engage in mathematically demanding subjects after compulsory [22]. The implications of mathematics anxiety and avoidance also impacts on students' decisions to pursue academic disciplines. Anxiety and mathematics avoidance are acquired phenomena and are often acquired through negative prior experiences of mathematics.

Closely associated with the issue of mathematical resilience is academic mindsets. Academic mindsets can impact on students' negative attitudes towards mathematics. Students either have a growth or fixed mindset. Students' with a fixed mindset consider their intellectual abilities as stable and inflexible to change. The terminology and literature associated with fixed mindset indicate that fixed mindsets are particularly prevalent in relation to mathematics. Students undertake tests and assessments to measure their mathematical ability which would indicate an assumption that students' mathematical ability remains fixed over time and is not susceptible to good teaching practices and at the same time, students are often told that if they try harder and work harder at mathematics, they will increase their attainment. Students in secondary school are often placed in groups based on their ability, and categorizing students in this manner would suggest a 'self-fulfilling prophecy'. Students placed in low ability groups may suffer from lower teacher expectations, may be given less challenging tasks which inevitably leads to attainment gaps between the groups. So the school system itself can reinforce ideas such as 'some people can do mathematics' and others simply cannot therefore reinforcing the idea of a fixed mindset. These ideas once ingrained in the 
learner can be difficult to offset and can make the process of learning mathematics much more difficult. Such ideas also enforce a sort of elitism associated with learning mathematics. Elitism is based on the assumption that only a minority 'can do' mathematics, which results in the helplessness developed in some learners, and which is accepted by the majority.

Teachers often deal with students who have a learned helplessness, who are discouraged or 'turned off' at the prospect of having to learn mathematics. For example, a student may try to remember all the steps in a mathematical procedure, inadvertently miss one step out and arrive at the wrong answer. If this happens frequently over time, the student learns that their effort does not achieve the outcome of the correct answer. Thus they conclude that their effort is not enough to achieve success in mathematics and next time the learner expends less effort. The consequences of maths anxiety, elitism, fixed mindsets and learned helplessness can result in large portions of the population avoiding mathematics.

Teachers, parents and society in general have a role to play in developing mathematical resilience in all learners. Teachers, in particular, play an extremely important role in developing positive attitudes and beliefs in all learners so that they can approach the learning of mathematics in a more positive manner. Mathematical resilience, a construct developed by [22], was designed specifically to work against negative influences. Mathematical resilience as characterized by a 'can do' attitude to any new mathematics encountered, a willingness to exert the effort needed to develop mathematical fluency and the ability to seek support when it is needed to overcome any barriers that impact on growth. Mathematical resilience pre-supposes that mathematics anxiety and learned helplessness can be overcome.

Engaging with learning mathematics may be viewed by some learners as a form of adversity, or as a 'means to an end', which just has to be done until they leave school and which can be avoided thereafter. The manner in which mathematics is presented and taught can cause learners to experience adversity. Rote learning procedures which emphasise practice for fluency, and which rely on working memory can instill mathematics anxiety in some learners as it can interfere with the recall of facts needed to solve a problem. However, it would be wrong to assume that students should learn mathematics in an untroubled manner. Mistakes can and will be made, however, mistakes provide an opportunity to learn. There are without doubt barriers to overcome when learning mathematics and struggle is part of the course. It could be stated that if students experience mathematics without challenge, then they will be ill-prepared for struggle in later studies.
The four aspects of mathematical resilience proposed by [22], include growth mindset, value of mathematics, the knowledge that mathematics involves struggle and knowing how to recruit help to support mathematical learning as defined below:

Growth mindset: developing an incremental or growth mindset

Value: understanding and experiencing mathematics as important in society and also personally. This aspect is also about the value of the individual as part of the mathematical community.

Struggle: An understanding of how to work at mathematics: that progress in mathematics requires struggle, curiosity and perseverance as well as learning to manage the emotions that come with learning something new.

Support: Knowing how to recruit support: an awareness of the value of collaboration, the use of conjoint agency to aid in the struggle to grow mathematical knowledge, skills and understanding.

Students who are mathematically resilient are charactersied as having a growth mindset and believe that their intellectual capabilities can be developed as opposed to being fixed and generally tend to be high achievers. [22] state that 'encouraging students to develop a growth mindset is ultimately about reminding students continually that when they practice new or different ways of doing mathematics, their brains develop ('just like a muscle') and they become more adept at dealing with the challenges of learning mathematics' (p. 10). Students who are mathematically resilient understand the value of mathematics, and feel included in the mathematics learning community. They also understand that their own position as part of the mathematics community is of value. Everyone has barriers to overcome when learning mathematics; students' can make mistakes or get stuck on a particular task and need perseverance. Mathematically resilient learners know that there is support available when faced with difficulties, and are not afraid to seek help when needed.

Resilient learners exercise agency in their learning. [22] state that 'learners develop agency through being allowed choice, independence and the opportunity to experiment' (p. 13). In order to facilitate the learning of mathematics in a resilient manner, the teacher must emphasise that there is no one fixed way when solving problems, and students must start from where they are and use what they know already and work to fit the new learning into their existing schemata. These sentiments are very much echoed in the Project Maths curriculum documents. 


\section{Methodology}

Research conducted for this study involved quantitative analysis to determine whether students who experienced Project Maths are mathematically resilient. In order to do so, a questionnaire examined students' attitudes towards mathematics as well as the academic mindsets deemed by [22] to be important for successful transition to tertiary level mathematics. Participants were also required to specify their perceived level of mathematical preparedness for higher education based on a 4 point scale with 1 - not at all prepared, 2 - slightly prepared, 3 - well prepared and 4 - extremely well prepared. The Attitudes Towards Mathematics Inventory (ATMI) by [19] was employed to measure attitudes in the three dimensions: value, enjoyment and self-confidence in mathematics. ATMI is based on a 5-point Likert scale that ranges from Strongly Disagree (1) to Strongly Agree (5). However, the results of an exploratory factor analysis revealed the presence of four factors: value of mathematics, enjoyment of mathematics, self-confidence in mathematics and maths phobia.

Participants were also required to specify their agreement with the following statements based on a 4 point Likert scale that ranges from 1 (strongly disagree) to 4 (strongly agree):

- $\quad$ I belong in this academic community

- My ability in this course will grow with effort

- My competence in this course will grow with effort

- I can succeed at this course

- The course activities have value for my future career

- The institutional environment is supportive

Academic mindsets are strongly associated with academic perseverance and achieving good grades [20] and are closely related to mathematical resilience. It was further stated in [20] that these academic mindsets are motivationally very powerful, and the more the student endorses these beliefs, the more the student will expend the effort to learn. This study examines whether the participants are mathematically resilient, by examining their attitudes towards mathematics, their academic mindsets and their perceived level of mathematical preparedness for higher education. The 6 academic mindsets were also subjected to an exploratory factor analysis, the results of which revealed that all 6 items loaded onto one factor, which did permit more robust findings.

Additionally, this study also examined whether participants who experienced the Project Maths Higher level curriculum feel more mathematically prepared for their higher education course than students who completed the Ordinary level curriculum. The importance of the affective domain on students as they negotiate the transition to higher education mathematics cannot be underestimated [3]. In particular it was found in [3] that affective factors have an impact on the mathematical preparedness of both Higher and Ordinary level mathematical students as they make the transition to higher education mathematics. This study will also investigate whether there are differences between gender and attitudes towards mathematics.

Students who participated in this study were first year engineering students from a variety of engineering disciplines including electronic engineering, mechanical engineering, civil engineering, building services and fire technology and a group of nursing students. Of the 93 first year students enrolled in engineering disciplines, fifty students in total participated in this study $(54 \%$ response rate). Only three of these participants were female, two of which are in the mechanical discipline and the other female is in the fire engineering discipline. Eight participants are in the electronics discipline, fifteen in the mechanical discipline, eleven in the civil discipline, seven in the fire engineering and nine in the building services discipline. Of the 54 nursing students enrolled in the nursing discipline, 39 participated in this study (72\% response rate), 13 were male and 26 were female. 89 students in total participated in this study.

\section{Analysis of findings}

Following an exploratory factor analysis which revealed the presence of four factors, attitudes towards mathematics were examined under the four dimensions: value of mathematics, enjoyment of mathematics, self-confidence in mathematics and maths phobia. The reliabilities for each factor were .929 for value of mathematics, .795 for enjoyment of mathematics and .915, self-confidence in mathematics and .924 for maths phobia.

Table 1. Mean scores for 4 ATMI factors

\begin{tabular}{|l|l|l|}
\hline ATMI Factor & Eng. & Nursing \\
\hline Value of Mathematics & $\begin{array}{l}3.94 \\
(.62)\end{array}$ & $\begin{array}{l}3.14 \\
(.69)\end{array}$ \\
\hline \multirow{2}{*}{ Enjoyment of Mathematics } & $\begin{array}{l}(.63) \\
\end{array}$ & $\begin{array}{l}2.80 \\
(.83)\end{array}$ \\
\hline Self- infidence & $\begin{array}{l}3.51 \\
\text { Mathematics }\end{array}$ & $\begin{array}{l}3.29 \\
(.86)\end{array}$ \\
\hline Maths phobia & 3.52 & 3.31 \\
& $(.77)$ & $(.83)$ \\
\hline
\end{tabular}


On a 5-point scale, the overall ATMI mean score for engineering students was 3.57 (std. deviation .64) and for nursing students was 3.05 (std. deviation .75). Table 1 below indicates the mean and standard deviation scores for each of the four factors.

Examining the four factors individually by means of individual t-tests revealed statistically significant relationships between discipline and value of mathematics $(\mathrm{p}<.001, \mathrm{t}=5.72$, df $=87)$ and enjoyment of mathematics $(\mathrm{p}=.001, \mathrm{t}=3.343$, df $=87$ ), while no relationship exists between the disciplines and self-confidence in mathematics $(\mathrm{p}=$ $.012, \mathrm{t}=2.553$, $\mathrm{df}=87)$ and maths phobia $(\mathrm{p}=.234$, $\mathrm{t}=1.197, \mathrm{df}=87$ ).

Only seven of the fifty engineering participants completed mathematics at higher level, all of whom had completed the Project Maths curriculum, forty two had completed mathematics at ordinary level, thirty eight of which had experienced the Project Maths curriculum and one participant entered 'other' for this statement in the survey suggesting that they had completed mathematics outside the Irish jurisdiction. Only 4 of the nursing participants completed the higher level curriculum and all nursing participants experienced Project Maths. The overall mean ATMI score for the 11 higher level participants was 4.01 (std. deviation .63) and was 3.23 (std. deviation .68) for the 77 participants who completed mathematics at ordinary level. Table 2 indicates the mean scores for value of mathematics, enjoyment of mathematics, self-confidence in mathematics and maths phobia for the participants who completed the ordinary level curriculum and the higher level curriculum.

Table 2. Mean scores for 4 ATMI factors (H.L - Higher level, O.L - Ordinary level)

\begin{tabular}{|c|c|c|}
\hline ATMI Factor & H.L. & O.L \\
\hline Value of Mathematics & $\begin{array}{l}4.12 \\
(.76)\end{array}$ & $\begin{array}{l}3.51 \\
(.74)\end{array}$ \\
\hline Enjoyment of Mathematics & $\begin{array}{l}4.02 \\
(.79)\end{array}$ & $\begin{array}{l}2.98 \\
(.93)\end{array}$ \\
\hline $\begin{array}{l}\text { Self- confidence in } \\
\text { Mathematics }\end{array}$ & $\begin{array}{l}3.82 \\
(.73)\end{array}$ & $\begin{array}{l}3.11 \\
(.77)\end{array}$ \\
\hline Maths phobia & $\begin{array}{l}4.08 \\
(.56)\end{array}$ & $\begin{array}{l}3.32 \\
(.79)\end{array}$ \\
\hline
\end{tabular}

In order to determine whether participants who completed the higher level mathematics have more positive attitudes towards mathematics, a MannWhitney U-test was performed. The Mann-Whitney U-test revealed a statistically significant relationship between attitudes towards mathematics and previous level of study. From the test it is apparent that participants who completed the higher level Project Maths curriculum have more positive attitudes towards mathematics $(\mathrm{U}=173, \mathrm{p}=.002, \mathrm{Z}=3.161)$. Examining the four factors individually by means of individual t-tests also revealed statistically significant relationships between previous level of study and all 4 factors of ATMI: value of mathematics $(\mathrm{p}<.012, \mathrm{t}=2.56, \mathrm{df}=86)$, enjoyment of mathematics $(\mathrm{p}=.001, \mathrm{t}=3.525$, $\mathrm{df}=86)$, selfconfidence in mathematics $(\mathrm{p}=.006, \mathrm{t}=2.816$, df $=$ 86 ) and maths phobia $(\mathrm{p}=.003, \mathrm{t}=3.029, \mathrm{df}=86)$.

Examining gender and attitudes towards mathematics, the overall ATMI scores for males was 3.40 (std. deviation .69) and for females 3.23 (std. deviation .69). This suggests that males display more positive attitudes towards mathematics. Table 3 indicates the mean scores for value of mathematics, enjoyment of mathematics, self-confidence in mathematics and maths phobia for participants based on gender. Males scored higher on 3 of the four factors of ATMI; value of mathematics, enjoyment of mathematics and self-confidence in mathematics. Employing a number of individual t-tests revealed that a statistically significant relationship exists for only one factor - value of mathematics $(\mathrm{p}=.002, \mathrm{t}=$ 3.238 , df $=87$ ) and no relationship exists between gender and maths phobia $(\mathrm{p}=.771, \mathrm{t}=.292, \mathrm{df}=87)$, self-confidence in mathematics $(\mathrm{p}=.528, \mathrm{t}=.646$, df $=87)$ and enjoyment of mathematics $(\mathrm{p}=.683, \mathrm{t}=$ $.410, \mathrm{df}=87$ ).

Table 3. Mean scores for 4 ATMI factors based on gender

\begin{tabular}{|l|l|l|}
\hline ATMI Factor & M & F \\
\hline Value of Mathematics & $\begin{array}{l}3.76 \\
(.69)\end{array}$ & $\begin{array}{l}3.23 \\
(.77)\end{array}$ \\
\hline Enjoyment of Mathematics & $\begin{array}{l}3.16 \\
(.93)\end{array}$ & $\begin{array}{l}3.07 \\
(1.08)\end{array}$ \\
\hline Self- confidence in & $\begin{array}{l}3.26 \\
(.74)\end{array}$ & $\begin{array}{l}3.14 \\
(.94)\end{array}$ \\
\hline $\begin{array}{l}\text { Mathematics } \\
\text { Maths phobia }\end{array}$ & 3.41 & 3.47 \\
& $(.80)$ & $(.84)$ \\
\hline
\end{tabular}

Only 27 participants in total indicated that they felt well prepared mathematically for higher education, while 5 participants indicated that they felt extremely well prepared mathematically. In contrast 56 participants indicated that they only felt slightly prepared mathematically and only 1 engineering participant stated that they felt not at all prepared mathematically for higher education. In order to determine if a relationship exists between 
previous level of study and mathematical preparedness for higher education, a Spearman's correlation test was performed. The test revealed a relationship does exist between mathematical preparedness and previous level of study ( $\mathrm{rs}=.254$, $\mathrm{p}=.016)$. In order to determine if a relationship exists between academic discipline and mathematical preparedness, mathematical preparedness was recoded into 1- not prepared (incorporating both not at all prepared and slightly prepared) and 2 prepared (incorporating well prepared and extremely well prepared) and performing a Mann-Whitney U test, revealed a statistically significant relationship between discipline type and mathematical preparedness for higher education $(\mathrm{p}=.008$, MannWhitney $\mathrm{U}=709.0, \mathrm{Z}=2.646$ ). 38 engineering participants felt not mathematically prepared for higher education in comparison to 19 nursing participants. Only 12 engineering participants and 20 nursing participants indicated that they felt mathematically prepared for higher education.

The 6 academic mindsets were also subjected to an exploratory factor analysis, the results of which revealed that all 6 items loaded onto one factor 'academic mindset'. The mean value for engineering participants was 3.44 (std. deviation .43) and for nursing participants was 3.31 (std. deviation .38). The boxplot as shown in figure 1 revealed that apart from a few outliers, engineering participants had slightly more positive academic mindsets when compared to the nursing participants.

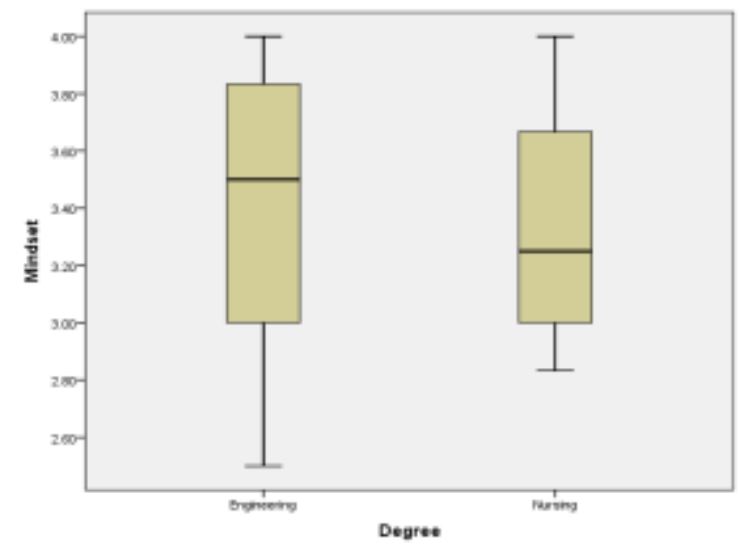

Figure 1. Boxplot of Mindsets per discipline

\section{Discussion}

Results for ATMI suggest that students have positive attitudes towards mathematics in general, and engineering students have slightly more positive attitudes towards mathematics than nursing participants. Engineering students in particular appreciate the value of mathematics to their chosen career in engineering. As $90 \%$ of engineering participants and $100 \%$ of nursing participants had experienced the Project Maths curriculum, this would suggest that Project Maths is having a positive effect in terms of students' attitudes towards mathematics. It also appears that nursing participants do not enjoy mathematics to the same extent as engineering participants. The results also indicate that students who completed the higher level curriculum tended to have more positive attitudes towards mathematics $($ mean $=4.01)$ than students who completed the ordinary level curriculum (mean $=3.23$ ). Those who completed the higher level mathematics curriculum also tended to perceive themselves as more mathematically prepared for higher education than students who completed the ordinary level curriculum. Engineering participants indicated that they did not feel as well prepared mathematically for higher education when compared with the nursing participants. This suggests that more needs to be done in secondary level school to support learners who wish to pursue mathematically intense STEM disciplines. The results of this research also suggest that males have more positive attitudes towards mathematics, however examining the individual factors of ATMI indicate that difference only exist in the value of mathematics. However, overall it is clear that Project Maths is having a positive impact on all students' attitudes towards mathematics.

Academic mindsets are strongly associated with academic perseverance and mathematical resilience as well as achieving good grades. The construct of mathematical resilience is important as it describes the positive attributes that learners need in order to prepare for and engage with mathematics both in school and beyond. It is necessary because of the negative emotions and exclusion which have been seen as to be engendered in many traditional approaches to learning mathematics. Mathematical resilience can be developed in all learners by using specific approaches to learning mathematics which foster communication and collaboration, and supported by teachers who encourage resilient learning behaviour when helping students overcome barriers to learning, sentiments which are strongly advocated by the Project Maths curriculum documents provided by the National Council for Curriculum and Assessment (NCCA). One of the factors of mathematical resilience is value, and this study has shown that both engineering and nursing participants have strong values in relation to mathematics, the mean score for value of mathematics for engineering participants was 3.76 (std. deviation.69) and for nursing participants was 3.23 (std. deviation .77). Further examining the value mindset statement 'the course activities have value for my future career' indicates that the majority of engineering and nursing participants do value course activities. The mean value for this academic mindset for engineering participants was 3.59 (std. deviation 
.64) and for nursing participants was 3.39 (std. deviation .49).

Another important aspect of mathematical resilience is a growth mindset. Mathematically resilient learners are aware that their competences and abilities will grow with effort and they will persevere in the face of adversity. Combining the mindsets statements 'my ability in this course will grow with effort' and 'my competence in this course will grow with effort' into one growth mindset ' $m y$ ability and competence will grow with effort' as suggested by [20], this study revealed that both engineering and nursing participants have strong and similar growth mindsets. The mean value for understanding that ability and competence will grow with effort for engineering participants was 3.38 (std. deviation .54) and for nursing participants was 3.36 (std. deviation .44). This suggests that the majority of new undergraduates have a growth theory of learning and know that their mathematical abilities.

Mathematically resilient learners are happy to engage with mathematics, understand its value and feel included within the learning community and most importantly they understand that learning mathematics involves a certain amount of struggle. When struggle is encountered, mathematically resilient learners know that they can engage appropriate supports and there is a community in which support can be obtained. Examining this factor on its own reveals that both engineering and nursing students know and understand that the academic institution in which they are studying is supportive. The mean value for knowledge of support for engineering participants was 3.52 (std. deviation .63) and for nursing participants was 3.31 (std. deviation .53). This indicates that in the face of adversity, both engineering and nursing disciplines are confident that support is available if needed. [20], also state the importance of feeling a sense of belonging during the transition to higher education. Examining the academic mindset 'I belong in this academic community' on its own reveals that both engineering and nursing participants have a strong sense of belonging in higher education. The mean value for 'sense of belonging' for engineering participants was 3.25 (std. deviation .58) and for nursing participants was 3.14 (std. deviation .54). This indicates that the majority of participants are content in their new role as tertiary students.

The six items from [20] which all loaded onto one factor following an exploratory factor analysis, revealed that the majority of participants have strong academic mindsets and are mathematically resilient. However, the researcher felt that it was important to report the individual results from the analysis of these academic mindsets given the importance that they place on determining whether new undergraduates are mathematically resilient. Given the results, it is possible to suggest that Project
Maths develops in the majority of learners' strong mathematical resilience. Students who endorse these 6 statements are more likely to invest effort in learning and to persist in the face of any adversity. This further suggests that engineering participants who reported feeling not prepared mathematically for higher education will be equipped to overcome any barriers they may encounter in tertiary mathematics. Research also suggests that when students care about what they are learning, set a clear path to developing their knowledge and skills, envision themselves on that path, and believe that their efforts will pay off, and trust that they will be supported when they need it are much more likely to work hard to learn [20]. The concept of mathematical resilience is important and teachers and lecturers involved in the delivery of mathematics need to be aware of its importance and be able to nurture it in all learners. The concept of mathematical resilience is built around established beliefs and research, and provides reasons to hope that the negativity surrounding mathematics can be dissipated and replaced with a positive image of mathematics, as well as student agency in learning, empowerment and control [22].

\section{Conclusion}

While previous research does recognise the importance of the non-cognitive domain during the mathematical transition to higher education, this study suggests expanding the non-cognitive domain to include academic mindsets as proposed by [20], which could determine whether new undergraduates are mathematically resilient. Mathematically resilient learners are more likely to transition more easily to tertiary level mathematics courses. Expanding the non-cognitive domain to include the academic mindsets which can determine whether new undergraduates are mathematically resilient has the potential to provide much greater information on the issues faced by students as they negotiate the transition to higher education and further demonstrates the multi-faceted nature of mathematical preparedness for higher education. Research also suggests that it is insufficient to consider grades alone and non-cognitive factors are equally important [21]. It is also stated in [21] that grades are becoming increasingly less useful as indicators of student achievement or as predictors of future student success and this is primarily due to grade inflation. Prior grades only provide a limited view of a student's potential [21]. While it is not possible to ignore grades, additional measures are important in assessing mathematical readiness for higher education. Non-cognitive factors typically refer to variables relating to adjustment, motivation and students' perceptions and differ from the traditional quantitative measures typically associated 
with examinations. Although this research focuses on first year engineering students, parallel studies could be considered across STEM disciplines to establish if these patterns exist in the wider group.

This study had several limitations, and since engineering is generally considered a male dominated discipline and nursing a female dominated discipline, the fact that only 1 female engineering participated and while 27 of the 39 nursing participants were female, still presents a limitation. In total, 62 participants in this study were male and 27 were female. However, to address gender balance, the questionnaire could be administered to a large body of undergraduate participants from a wide range of disciplines including science, engineering, computing, business, accountancy and nursing which has the added advantage of increasing sample size.

\section{Acknowledgements}

Thanks are extended to all of the engineering and nursing students who willing gave their time to respond to the questionnaire.

\section{References}

[1] Treacy, P., Faulkner, F. and Prendergast, M. (2016). Analysing the correlation between secondary mathematics curriculum change and trends in beginning undergraduates' performance of basic mathematical skills in Ireland, Irish Educational Studies, 35 (4), 1-21.

[2] Grove, M. (2012) The Mathematical Transition: A twostage problem? MSOR Connections, 12 (1), 15-18.

[3] Hourigan, M. and O'Donoghue, J. (2007). Mathematical under-preparedness: the influence of the pretertiary mathematics experience on students' ability to make a successful transition to tertiary level mathematics courses in Ireland. International Journal of Mathematics Education in Science and Technology, 38 (4), 461-476.

[4] Daskalogianni, K., and Simpson, A. (2002). Coolingoff: The phenomenon of a problematic transition from school to university. In Proceedings of the second international conference on teaching mathematics at the undergraduate level (pp. 103-110).

[5] Bourn, J. (2007). Staying the course: the retention of students in higher education. London: National Audit Office.

[6] Faulkner, F., Hannigan, A. and Fitzmaurice, O. (2014) The role of prior mathematical experience in predicting mathematics performance in higher education. International Journal of Mathematical Education in Science and Technology, 45 (5), 648-667.

[7] Gill, O. (2006) What counts as Service Mathematics? An investigation into the 'Mathematics Problem' in Ireland, (PhD): University of Limerick.
[8] National Council for Curriculum and Assessment (NCCA) (2012). "Project Maths Responding to current debate", [internet], Dublin, Ireland, http://www.ncca.ie/en/Curriculum_and_Assessment/PostPr imary_Education/Project_Maths/Information/Project_Math s_response_to_current_debate.pdf (Access Date: 2/12/2016)

[9] Kantanis, T. (2000) The Role of Social Transition in Students Adjustment to The First-Year of University. Journal of Institutional Research, 9(1), 100-110.

[10] Jones, B. and Frydenberg, E. (1998) Who Needs Help and When: Coping with The Transition from School to University, Annual Conference of the American Educational Research Association, 1-27.

[11] D'Souza, S., and Wood, L. (2003) Tertiary Students' Views about Group Work in Mathematics. Proceedings of the Australian and New Zealand Associations of Research in Education Joint Conference. Auckland, New Zealand.

[12] Treacy, P., and Faulkner, F. (2015). Trends in Basic Mathematical Competencies of Beginning Undergraduates in Ireland, 2003-2013. International Journal of Mathematical Education in Science and Technology, 46(8), 1182-1196.

[13] Carr, M., Bowe, B. and Ní Fhloinn, E. (2013). Core Skills Assessment to Improve Mathematical Competency. European Journal of Engineering Education, 38(6), 608619.

[14] Higgins, P. J., Mullamphy, D., and Belward, S. R. (2010). Bridging the gap: teaching university mathematics to high school students. Australian and New Zealand Industrial and Applied Mathematics Journal, 51, C640C653.

[15] Clark, M., and Lovric, L. (2009). Understanding secondary-tertiary transition in mathematics. International Journal of Mathematical Education in Science and Technology, 40(6), 755 - 766.

[16] Conley, D. T. (2007). Toward a more comprehensive conception of college readiness. Eugene, OR: Educational Policy Improvement Center.

[17] Duncheon, J. (2013). The problem of college readiness. Paper presented at annual meeting of the Association for the Study of Higher Education, St. Louis, MO.

[18] Killilea, M., O'Brien, S and Delargey, M. (2014) Sociocultural lessons for reform-based mathematics: Tracing pedagogical shifts in a transition year classroom CASTeL (Centre for the Advancement of STEM Teaching and Learning) (2014) Science and Mathematics Education Conference, 102-116

[19] Tapia, M. and Marsh, G. E. (2004) An Instrument to Measure Mathematics Attitudes. Academic Exchange Quarterly, 8(2), 16-21. 
[20] Farrington, C. A. (2014). Failing at School: Lessons for Redesigning Urban High Schools. Teachers College Press: place.

[21] Sedlacek, W.E. (2011) Using Noncognitive Variables in Assessing Readiness for Higher Education. Readings on Equal Education, 25, 187-205.

[22] Lee, C. and Johnston-Wilder, S. (2014). The Construct "Mathematical Resilience". In S. Chinn (Ed.) The international handbook for mathematical difficulties and dyscalculia, Routledge. 